\title{
Analysis of Motivational Elements of Social Games: A Puzzle Match 3-Games Study Case
}

\author{
Marcel Toshio Omori and Alan Salvany Felinto \\ Computer Sciences Department, State University of Londrina, Londrina, PR 86051-980, Brazil \\ Correspondence should be addressed to Marcel Toshio Omori, marcelomori86@gmail.com
}

Received 27 August 2012; Revised 30 November 2012; Accepted 14 December 2012

Academic Editor: Daniel Thalmann

Copyright (C) 2012 M. T. Omori and A. S. Felinto. This is an open access article distributed under the Creative Commons Attribution License, which permits unrestricted use, distribution, and reproduction in any medium, provided the original work is properly cited.

\begin{abstract}
The main motivational elements of the social network sites and the social network games will be shown according to studies already existent in the literature, highlighting the elements which motivate the players the most to play social Match 3-type games. Seven games have been analyzed: Diamond Dash, Collapse! Blast, Mystic Ice Blast, Bricks Breaking, Plock, Gem Clix, and Blast!. The results showed that asynchronous time, activities publishing, rewarding system, competition, and social status are the elements which motivate and stimulate the most the players to play.
\end{abstract}

\section{Introduction}

The social network sites show a great number of users [1], in particular Facebook which at the end of December 2011 owned more than 845 million active users per month [2]. At the same time, the social network games also prove a great popularity, an example is the game FarmVille present at the Facebook which in 2010 achieved a mark of 76 million active players per month [3]. Other more recent examples are Angry Birds Friends with 12 million active players per month and the most recent release of the game FarmVille, FarmVille 2, with more than 60 million active players per month [4].

Despite the success of these games, the social games have a lot of challenges to overcome, and one of them is attractiveness [5]. What are the elements which attract the players? Why do people play social games? There are a lot of studies at the literature about guides on good practice to develop interfaces, mechanics, gameplay, and ideal stories for the games [6], but for the social games which appeal more to the emotional side than to the actions themselves $[3,7]$, it is also necessary to identify the main personal, social, and psychological elements which motivate and stimulate the players to play. There are some studies about this emotional side such as the ones by Ines and Abdelkader [3], although the analysis is generally aimed at all kinds of games. At this study, we have focused on identifying the main motivational elements of the social Match 3-type games. One example of this type of game is Diamond Dash which has 19 million active players per month [4].

The goal of this kind of game is to destroy the greatest number of gems as possible within a determined period of time and obtain points. In order to destroy the gems, the player must find and click on the gems which have combinations of three or more gems of the same color. The mechanics of the game demand that the player should have a good visibility and mouse handling.

How come games which possess so simple arts, sounds, mechanics, and gameplay to the point of being developed in a short period of time of two months can attract millions of players? This study will not answer this question, but it will take the first step towards this discovery by means of the identification of the main motivational elements of the social Match 3-type games.

In order to identify the main motivational elements of this kind of game, we have chosen 7 games and requested a group of "gamers" of a university to evaluate them. There were 12 applicants altogether. The result of the evaluation will be shown at the following chapters.

The paper is divided into 7 sections. Section 2 brings some concepts about the social networking and its features, in particular Facebook. In Section 3, it will be shown the 
concepts about casual and social games, the difference between them, and their characteristics. Section 4 identifies the main motivational elements of the social network sites and the social network games according to studies already existent at the literature. In Section 5 it is explained the adopted analysis methodology. Section 6 shows the analysis results. Finally, In Section 7, it will be shown the discussions and the conclusions. Moreover we clarify the conflict of interests of this study by the end of the paper.

\section{Social Network Sites}

Social network sites (SNSs) are services based on the web which allow the person (1) to create a public or semipublic profile within a limited system, (2) to articulate a list of friends with whom he or she shares connections, and (3) to see and search through a list of connections which have the profiles created by other users of the system [8].

The social network sites are unique as they make it possible for the users to articulate and to make their social networks visible, and not for the fact that they allow to find friends and create new contacts [8]. At the majority of the SNSs, the individuals communicate mainly with people who are already part of their social network, that is, they are not necessarily looking for new friendships. The social network consists of visible profiles which show a list of friends who are also users of the system. The public viewing of these connections is the crucial component, inasmuch as it is through this list that the users are able to browse through the network [8].

2.1. Case Study: Facebook. Facebook is a social free network site, and its revenue is obtained by means of publicity, advertisement, and sponsors.

Facebook owns more than 800 million active users, and more than half of them access the website every day. On average, each user has 130 friends and spends 55 minutes a day at the website. Every 20 minutes, approximately 1.4 millions of invitations for events are sent, 1.8 millions of updates, status are done, 2.7 millions of messages are sent, 1 million of links are shared, more than 2.7 millions of uploads of pictures are accomplished, and 1.9 millions of friendship requests are accepted. Facebook is available in more than 70 different languages, and more than 200 million people a day access the website by using mobile gadgets [2]. Facebook is considered the greatest online SNS of the world [9].

The elements which facilitate the interaction include list of friends, wall, pokes, status, events, photos, videos, messages, chats, groups, and like. The list of friends is the Facebook's crucial element once the users can make it public and make it possible for others to browse the network through it. The wall is a term used for the Facebook tool which works as a notice board where the users post personal messages straight to another individual. Users can share photos, videos, and messages at the wall [10]. Besides, people can begin a greeting with others through the pokes service. Status is used to inform about the user's activities. The tool events allows to plan meeting or events and to invite other people to participate. The photos and videos resources allow the user to upload albums, photos, videos, and comments. The communication with friends takes place through chatting and messages which can be private or public. People can create and/or affiliate in groups of interest by using the groups service. With the functionality like, the user can give a positive feedback about a determined content shared by their friends [2].

Due to the social and technological features, Facebook reached millions of users and became inserted at the people's day-by-day, becoming the center of attention of researchers in several aspects, such as the online and offline relationship functioning, at the technological features of the social communication networks and at the cultural differences when using this virtual environment [10].

2.2. Applications. Facebook's applications like the games are not part of the social network; they are external tools which can be added or installed at the user's profile. When the user starts to use some application, all of his or her friends will know about that, as the SNS informs all his or her friends about the fact. This is the first social interaction of the game [1].

Most of the Facebook's applications are not classified as a game, as they are relatively simpler than the other casual games, and they do not offer complex gameplay; generally, they are one- or two-click actions at the most. In order to accommodate all these applications which do not meet all the gaming requirements, the Facebook managers introduced a new category of games called Just for Fun [11].

Facebook's games appeal more to the emotional side (fun and humor) rather than to actions (gameplay). Instead of modeling and stylizing concrete actions for the gameplay, which characterizes the games, Facebook's applications reduce these activities to a few clicks and focus on the interaction and expression features of the players [7].

\section{Casual and Social Games}

According to the International Game Developers Association [12], the casual games are applications addressed to consumers in general, that is, for those who are not gamers. This definition applies to the Facebook users, as most of them are not hardcore players [3]. In general, these kinds of games demonstrate simple gameplay; they are easy to play, consume little time from five to twenty minutes, and they focus on entertaining and casualness [12].

The social network games (SNGs), in turn, are applications which use the SNS infrastructure and resources [13] and demonstrate asynchronous gameplay and mechanisms for multiple players [5]. At the traditional computer games, consoles, and cell phones, people play at the singleplayer or multiplayer modes against strangers. At the social games, the individuals play with friends and family members, which increases the attractiveness and entertainment of the game [1].

In comparison with the traditional games which have well-elaborated audio and graphics, the social games are 
relatively way simpler and demonstrate a lower development cost. According to D. H. Shin and Y. J. Shin [5], the development of conventional games might cost something around $\$ 2$ million to $\$ 3$ million, and the social games might cost something around $\$ 100.000$ to $\$ 300.000$ and generally consume less time to be developed; with several designers, the game release might last around 2 to 3 months. Another interesting fact is that the social games are most of times free of charge, which facilitates its distribution. Profit, at this case, is obtained through advertisement, marketing, virtual assets, and coins sales.

By analyzing some games, Rossi [1] classified the social games into two categories: skill/knowledge and truly social. At the former, the players carry out activities to get points which are exhibited publicly in rankings and/or social network site, which defies the players and creates competitions among them. At this case, the social status issue is the main characteristic of the game, as even if this does not offer entertainment, the users play in order to overtake their friends and to be the top at the ranking. Games such as Crazy Planets, Minigolf Part, Geo Challenge, Word Challenge, Bowling Buddies, and Who Has The Biggest Brain? are some examples of skill/knowledge games. Now, the truly social games show as main element the product management. The games Restaurant City and Pet Society are some examples of this category. At the former, the player is supposed to run the restaurant, and at the latter, he or she has to take care of his or her pet. In both cases, the social interaction occurs at the game itself, as the players must help each other in order to progress, the friends are not competitors, and the social networks are necessary strategical resources to play. So, the more friends the person has in his or her network, the more benefits he or she will obtain.

According to Sung et al. [14], the female audience is more active at the social games than men due to the fact that women feel more attracted for applications which offer more interaction and dialogues rather than actions.

\section{What Are the Elements That Motivate the Users to Play?}

Based on the studies existent at the literature, this topic will show the main characteristics and elements which motivate and stimulate the users to play SNGs.

4.1. Mechanics of the Social Network Games. According to Hamari and Järvinen [15], the mechanics of the game are a set of standard activities which are divided into two dimensions: the player dimension and the system dimension. The first one has the activities which the player can carry out in order to interact with the other players or with the game itself, and the second has the procedures which the system carries out according to the activities carried out by the player. Every mechanics of the game is directly related to the objectives of the game once the users carry out the activities in order to perform the objectives, and the system provides feedback related to the objectives. A practical example is present at the game FarmVille where the players harvest the fruits (player activity) and the system rewards him or her with coins of the game (system procedure).

At the SNGs, the social interaction tools provided by the SNSs are adapted at the mechanics of the game, that is, the mechanisms of relationship are inserted at the dimension of the game [15]. The game FarmVille shows these kinds of mechanisms, as the player has his or her personal objectives, to manage the farm, and he or she can interact with his or her friends through messages and by publishing the activities related to the game at his or her profile.

According to studies by Hamari and Järvinen [15], the mechanics of game which assure entertainment at the social games are the acquisition, retention, and monetization mechanics. The first mechanics is related to the items that the player can purchase during the game. Donating and receiving gifts and having friends as resources or helpers are some examples of acquisition. Now, the retention mechanics are related to the activities that the player perform in order to keep his or her items with himself or herself. An example is daily bonuses where the player obtains rewards for each day that he or she returns to play. Finally, the monetization mechanisms are the activities related to the purchasing of items or upgrades with real currency or the games currency. Some examples are the items which must be purchased so that the player can progress at the game or some upgrades which expire along the time and suggest that the player buy them again.

4.2. Time and Action Space. The social games show asynchronous gameplay, that is, the players do not need to be necessarily online at the same time to play [5]. Another time factor present so much at the truly social games is the presence of components which operate even at the absence of the player. For example, at the game FarmVille, the player can crop several fruits where each of them has a different time of ripening (some of them take hours and others take days) which after being planted, germinate and grow within a determined time even if the player is not present at the game. This tactics allows the player to adapt the game at the day-byday, besides stimulating him or her to return to play, as if he or she does not return in time to harvest the fruits, these ones would rot and the player would not receive the rewards. It is realized that the time factor is an important characteristic at the social games as it allows the player to adapt the game according to his day-by-day [5]. Furthermore, Meurs [16] claims that this characteristic is ideal for the casual players who, on the contrary to the hardcore players, are not willing to spend a lot of time on games, which is characteristic of Facebook users [3].

Now, the action space of the social games is a personal environment and is not shared, as the presence of friends is symbolic and social interactions are fictitious [3]. The real interaction occurs through the SNS when the player performs any activity at the game and this is published for all of his or her friends. For example, at the game FarmVille, the player cannot interact with the friends' farms, but he or she can visit them, which creates an interaction feeling at the game, and it creates the real socialization through the social network site. 
Benkler [17], Urista et al. [18], Joinson [19], and Lucas and Sherry [20] claim that the social interaction is one of the factors which motivate the users to make use of the SNSs.

4.3. Gratification. Uses and Gratification (U\&G) is a framework used to study how the media like the social media are used to satisfy the needs of different individuals with different objectives [21]. According to the analysis of Hou [22], gratification can be defined as the expectation of each individual related to media.

The gratifications of the social games according to Lucas and Sherry [20] are these six elements: competition, challenge, social interaction, fun, fantasy, and excitation. Among these, Sherry et al. [23] and Hamari and Järvinen [15] highlighted the competition as the most motivating element. Hou [22] pointed out the social interaction as a determining factor to encourage the players to play social games. Despite the fact that the fantasy has been cited as one of the motivations at the studies of Lucas and Sherry [20], Hou [22] showed at his studies that this element cannot bring positive results for the games, as many times, fantasy does not satisfy the expectations of the all the players.

According to Benkler [17], the social connectivity, psychological well-being, gratification, and material gaining are the main elements which motivate the users to use the SNSs. Urista at al. [18] claim that efficient communication through photos, music, videos, e-mails, and messages is the great gratification when using the social media. Still according to the author, efficient communications, curiosities about the others, popularity, and relationships are the main factors which motivate the users to use the social network sites. Joinson [19] also pointed out the social connectivity, identity sharing, contents, social investigation, and status updating as other motivation factors. Now, Kollock [24] pointed out the reciprocity, reputation, efficacy, fondness, and needs of group as some of the main elements which contribute and motivate the users to participate in online communities.

4.4. Murray's Psychological Needs at the Social Games. According to Ines and Abdelkader [3], the success of the social games at Facebook is assured by the five Murray's psychological needs: material needs, power needs, affective needs, ambition needs, and information needs.

The material needs refer to the activities involving gaining, acquisition, retentions, construction, and organization [25]. The material gain cited by Benkler [17] as one of the motivations to use the SNS and the acquisition, retention, and monetization mechanics present at the games which according to Hamari and Järvinen [15] assure the entertainment can be inserted into this context. At the game, these needs can be satisfied through purchases and items gaining, coins, daily bonuses, among others. For example, at the game Angry Birds Friends, the player gains items for each day that he or she returns to play.

Concerning the power needs, these are related to the activities of humiliation, autonomy, aggression, respect, and dominance [25]. The motivational elements cited by other author, like reputation [24], competition [15, 20, 23, 24], and social status [3] can be grouped at this necessity. One of the most common examples present at the games which meet these needs is the level mechanism. The player starts at level one, and gradually, along the progress or acquired experience at the game, his level will go up and consequently his or her social status. Hamari and Lehdonvirta [26] say at their studies that releasing new items for each level motivates the players to wish those products, which creates relation between the power needs and material needs.

The affective needs are related to the affiliation, group, rejection, care, and fragility activities [25]. People for being social creatures are constantly searching for other individuals to share interests, solve problems, meet, talk, ask for help, among others. All the related elements with these activities can be inserted into the context of affectivity. The main elements identified by Kollock [24] which contribute for the people to take part of online communities are reciprocity, fondness and group necessity as some examples. At the game FarmVille, for example, in order to increase his or her storage space, the player must ask for his or her friends' help to click on a link, and if he or she can have 10 clicks, the player obtains the extra space and his or her friends will get games coins for having helped.

Ambition needs are related to all the activities which generate accomplishment, exposure, and recognition [25], that is, they are activities which are related to personal satisfaction to reach or accomplish some objective. The challenge element identified at the studies by Lucas and Sherry [20] as a gratification element of the social games can be considered as part of this necessity. The presence of ranking at games like Diamond Dash satisfies these needs, as the player has the objective to overtake his or her friends and to be number one of the ranking and his or her score is shown to other players, which exposes his or her achievements and generates recognition.

Finally, the information need refers to the activities to obtain knowledge, educate, and keep updated [25]. All the elements and communication resources such as chatting, email, list of friends which are using the same application, online and offline status, and registration of the last activities of friends can be inserted into this necessity. At the games, the information needs can be satisfied through tutorials and continuous feedback which teach the user to play and show what he or she is doing. Choi and Kim [27] also claim that tools of communication stimulate the players to continue playing.

4.5. Playfulness. Like the other kinds of games, the success of the social games depends on game elements which retain the individual attention and involve him or her at the entertainment and satisfaction activity [3], which is denominated ludic, although its concept does not imply only the interests, abilities, challenges, or attention, as the playfulness is a state of mind and it mixes the cognitive spontaneity, social spontaneity, physical spontaneity, gladness manifestation, and sense of humor. This state of mind represents the willingness and is considered more important than entertainment itself, as first, it is the mind attitude 
which creates the preliminary to play and prepares the conditions for opportunities emerging and the actions to play and second, is just the external manifestation of this attitude [11]. The interesting part of this definitions is that it embodies not only the personal aspects but also the social ones, and both of them are main elements for the creation of playfulness which creates conditions and social situations so that the people express the personal meanings in a social structure [11]. Facebook is an example of that, as it uses the individual entertainment and the social tools, which makes that the users themselves create playfulness [3]. Curiously, the Facebook applications appeal more to the emotion and moods state than to actions themselves, which can be realized by the simple gameplay in the majority. One example is Mafia Wars, as to play it, the user only needs to click on a button to carry out a mission and acquire experience, and even with a very simple gameplay, the games has more than 27 million active players per month, which shows that there is something else besides its gameplay which stimulate the users to play [3]. Playfulness is present in all kinds of games regardless the platform [28].

4.6. Flow. The "flow" concept was defined by the psychologist Csikszentmihalyi [29] as one focus state, pleasure, and entertainment; the person's attention is captured completely by something and the individual loses the notion of time and of everything around him or her and concentrates only at what is grabbing his or her attention. According to Schell [30], the game designers have as objective to create experiences interesting enough to attract the players' attention and to put them in "flow" state. To keep the players in this ideal state, it is necessary to have a balance between the abilities of the player and the challenges of the game, that is, the challenges must be proper for the current experience of the player, not very hard, not very easy, and the game must keep the balance between failure and success. Csikszentmihalyi [29] gives example of a student who is learning how to play tennis. At the beginning, the student will have no ability, and therefore the coach starts with basic and simple training sessions, which is still a challenge and fun for the student. As the student acquires new abilities, it is necessary that the coach shows new activities and new challenges, inasmuch as the basic tasks are already boring for the student. This concept comprises all kinds of activities, and thus it can be also applied at the SNGs.

4.7. Intrinsic and Extrinsic Motivations Theory. According to studies by Chang and Chin [9], intrinsic motivation is characterized by performing of one task with no apparent effort an individual, as the activity itself is fun to be carried out, that is, the action itself is the reward for the individual. People will be more willing and will have more persistence in their intentions and behaviors when they are influenced by intrinsic motivations; so, entertainment is positively related to the motivation of playing.

Extrinsic motivation is defined as the performance of an activity in order to obtain a result or a reward [9]. Examples of extrinsic motivation are the ease of use and the usefulness.
Ease of use refers to the degree the person will not have difficulties when using an application or system. Now, the usefulness is defined as the degree of improvements and the performance of the task when using a specific tool. So, if a social game is useful and demonstrates to be easy when using it, the users will have good incentive to play [9].

4.8. Questions about Privacy and Security. The questions about security and privacy at the social games, such as spam, accounts hijacking, and data and identity (ID) thefts are numerous and reduce the gameplay of the social games and consequently decrease the pleasure to play; however, the positive facts such as entertainment generally distinguish themselves against the negative aspects, that is, the players are influenced more by the positive factors than by the negative factors [5].

4.9. Virality. Virality is a very important concept at the SNSs [15]. Helm [31] defines marketing viral, virality for marketing, as the following:

\section{"Viral marketing can be understood as a com- munication and distribution concept that relies on customers to transmit digital products via electronic mail to other potential customers in their social sphere and to animate these contacts to also transmit the products."}

It is possible to realize that the developers use this practice to publish their games through the social network site. The publications are done through solicitations, invitations, events, and games activities which are sent for friends or are published at the user profile, where his or her friends can visualize them, to get interested and start to play. Wei et al. [32] points out this practice as a main element to the propagation of the games, as it reaches a great amount of users in a short period of time.

4.10. Kinds of Players. The segmentation is a main concept present at the marketing literature, and its objective is to separate people into groups according to their characteristics. This practice is used by companies in order to direct its products for the proper clients. According to Hamari and Tuunanen [33], the marketing literature classifies the people into the following four main categories:

(1) geographic: classification of people according to address, city, state, country, among others. In the context of the games, the preference of the players can be influenced according the culture of his or her culture or continent [33];

(2) demographic: classifications done according to age, gender, education, social status, occupation, among others. For example, the average age of the students is 25 years old;

(3) psychographic: classification done according to attitudes, interests, or lifestyle of the person (e.g., extroverted people); 
(4) behavioral: classification done according to the behavior of a person concerning the product (e.g., the player who plays every day during the work break).

Hamari and Tuunanen [33] claim in their studies that for the analysis for the kinds of players, the researchers do not show very interest in geographic and demographic segmentations.

Still according to Hamari and Tuunanen [33], Bartle is one of the authors with greater references for studies of player types. Through the behavioral analysis of the players at the games type MUD (Multi-User Dungeon), Bartle [34] defined two dimensions of kinds of players: actions versus interaction and player-orientation versus world-orientation, as it is shown in Figure 1. The kind of player is determined depending on the position in each of the axes (actions versus interaction and player-orientation versus world-orientation). The player will be the type Killer if he or she prefers actions and if he or she is player-oriented, and he or she will be explorer if he or she prefers interaction and if he or she is world-oriented.

Hamari and Tuunanen [33] claim that the kinds of Bartle players have a lot of criticism, and the most important one is that the behaviors of the players may vary during the time, which makes it impossible to determine in which category the player fits, although the player typology of Bartle is sufficiently useful to describe all kinds of possible players.

Yee [35], with the use of typology of players of Bartle, defined three factors which motivate the players to play online games: achievement, social aspects, and immersion. The factor achievement can be categorized at Murray's ambition needs.

4.11. Motivational Elements of the Social Games. Based on the studies demonstrated at the previous topics, we have identified the main motivational elements of the social games present at the literature, as Table 1 shows.

Some elements (subelements), due to the fact that they demonstrate the same principle, were grouped in wider elements (elements). For example, competition and social status were inserted at a more general context which is power needs.

The elements playfulness, intrinsic and extrinsic motivations, flow, and security were inserted at the context of the game elements as they are items which are related to the characteristics that the game itself demonstrate which attract the player attention. The playfulness refers to the satisfaction and entertainment that the game offers to the player. The intrinsic and extrinsic motivations are related to the usefulness of the game. Flow is used by the game designers to elaborate games with activities which grasp the player's attention. Security is related to the strategies and resources used at the game to offer greater safety to the user.

\section{Methods}

For the evaluation, it was chosen Match 3-type games as these ones demonstrate simpler gameplay and mechanics, which does not need very broad analysis related to the characteristics of the game itself, and like this, it allows to focus the research more on the personal, social, and

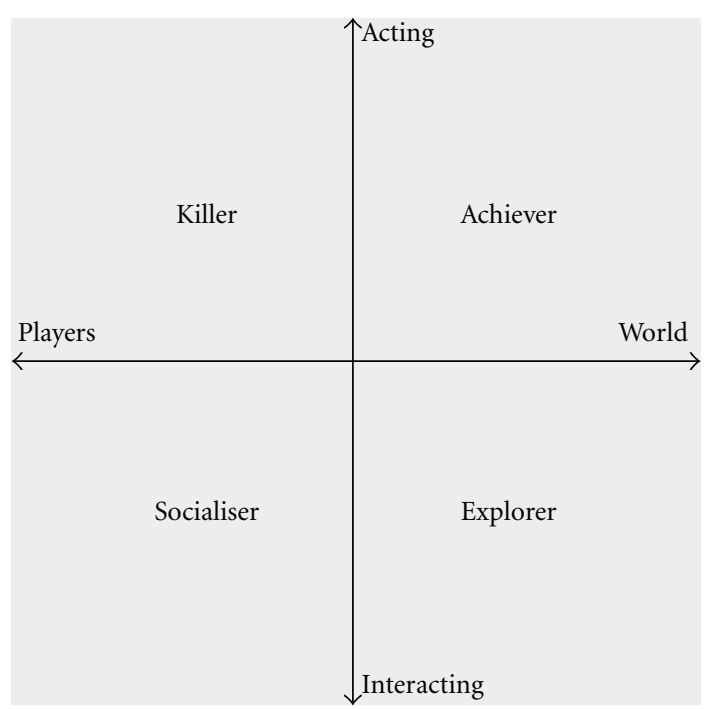

Figure 1: Bartle’s player typology.

psychological aspects of the game which is the objective of this study. Another reason is that to analyze simpler games allows a faster and more precise analysis. All the 7 selected games are the same type (Match 3 ) and have similar gameplay and mechanics as it is shown in Figure 2. It was adopted this criterion as the results may vary for each type of game, for example, the preferences of the players may vary from a game to another, typology of Bartle players [34], and like this, a motivational element which is prominent for a game might not be for another one. The selected games for evaluation were Diamond Dash, Collapse! Blast, Mystic Ice Blast, Bricks Breaking, Plock, Gem Clix, and Blast!.

The participants are 12 "gamers" selected from a group of games of a university where 10 are males and 2 are females, 9 are computer science undergraduate students and 3 are music undergraduate students, and all of them are Brazilian. Each participant played all the games and evaluated the level of presence of each motivational element of each game with values between 1 and 5 , where 1 meaning the lowest presence and 5 meaning the highest one. There is a definition of each value as follows:

(1) it does not have: the game did not show any characteristic of the motivational element;

(2) slightly visible: the game has the motivational element, but its presence at the game is minimum;

(3) visible: it is possible to notice the presence of the motivational element at the game;

(4) present: it is noticed easily the presence of the motivational element at the game;

(5) clearly present: the motivational element is present at the game in a clear and objective way. 
TABLe 1: Main motivational elements of the social games.

\begin{tabular}{|c|c|c|c|}
\hline Authors & Elements & Subelements & Examples \\
\hline $\begin{array}{l}\text { D. H. Shin and Y. J. Shin 2010; Meurs } \\
2011[5,16]\end{array}$ & Time & Asynchronous time & Single player \\
\hline \multirow{2}{*}{$\begin{array}{l}\text { Ines and Abdelkader 2011; Benkler 2006; } \\
\text { Urista et al. 2009; Joinson 2008; Lucas } \\
\text { and Sherry 2004; Hou 2011; Wei et al. } \\
2010[3,17-20,22,32]\end{array}$} & \multirow{2}{*}{$\begin{array}{l}\text { Social } \\
\text { interaction }\end{array}$} & Social fictitious presence & \multirow{2}{*}{$\begin{array}{l}\text { To help and to hire friends } \\
\text { Wall post, send invitation for friends to } \\
\text { play }\end{array}$} \\
\hline & & Publication of the activities & \\
\hline $\begin{array}{l}\text { Ines and Abdelkader 2011; Hamari and } \\
\text { Järvinen 2011; Benkler 2006 [3, 15, 17] }\end{array}$ & $\begin{array}{l}\text { Materialistic } \\
\text { needs }\end{array}$ & Rewarding system & Daily bonuses \\
\hline $\begin{array}{l}\text { Ines and Abdelkader 2011; Kollock 1999; } \\
\text { Lucas and Sherry 2004; Hamari and } \\
\text { Järvinen 2011; Sherry et al. 2006; Hamari } \\
\text { and Lehdonvirta } 2010 \\
{[3,15,20,23,24,26]}\end{array}$ & Power needs & $\begin{array}{l}\text { Competition } \\
\text { Social status }\end{array}$ & $\begin{array}{l}\text { Ranking, weekly championships } \\
\text { Level }\end{array}$ \\
\hline \multirow{2}{*}{$\begin{array}{l}\text { Ines and Abdelkader 2011; Joinson 2008; } \\
\text { Kollock } 1999[3,19,24]\end{array}$} & \multirow{2}{*}{ Affective needs } & Cooperation & To help friends \\
\hline & & Interest sharing & $\begin{array}{l}\text { Gifts (to donate and to receive presents), } \\
\text { group needs }\end{array}$ \\
\hline $\begin{array}{l}\text { Ines and Abdelkader 2011; Lucas and } \\
\text { Sherry } 2004[3,20]\end{array}$ & $\begin{array}{l}\text { Ambition } \\
\text { needs }\end{array}$ & - & Objectives, challenges, achievements \\
\hline $\begin{array}{l}\text { Ines and Abdelkader 2011; Choi and Kim } \\
2004[3,27]\end{array}$ & $\begin{array}{l}\text { Information } \\
\text { needs }\end{array}$ & Cognitive spontaneity (learning) & Feedbacks, tutorials \\
\hline \multirow{4}{*}{$\begin{array}{l}\text { Schell 2008; Rao 2008; Benkler 2006; } \\
\text { Chang and Chin 2011; D. H. Shin and Y. } \\
\text { J. Shin 2010; Csikszentmihalyi } 1990 \\
{[5,9,11,17,29,30]}\end{array}$} & \multirow{4}{*}{ Game elements } & Playfulness & \multirow{4}{*}{$\begin{array}{l}\text { Arts, sound, gameplay, mechanics, story, } \\
\text { fantasy, plot }\end{array}$} \\
\hline & & Intrinsic and extrinsic motivations & \\
\hline & & Flow & \\
\hline & & Security & \\
\hline
\end{tabular}

TABLE 2: Level of presence of the motivational elements at the Match 3-type games.

\begin{tabular}{|c|c|c|c|c|c|c|c|}
\hline Game & DiamonD dash & Collapse! Blast & Mystic Ice Blast & Bricks Breaking & Plock & Gem Clix & Blast! \\
\hline Asynchronous time & 4.5 & 4.3 & 4.2 & 4.1 & 4.1 & 4.8 & 4.6 \\
\hline Fictitious social presence & 2.4 & 2.2 & 2.6 & 1.9 & 2.8 & 1.9 & 1.4 \\
\hline Activities publications & 4.3 & 3.4 & 3.7 & 3.0 & 3.0 & 3.1 & 2.0 \\
\hline Rewarding system & 4.7 & 3.9 & 3.6 & 1.6 & 2.4 & 2.4 & 1.3 \\
\hline Competition & 4.3 & 3.5 & 3.0 & 2.3 & 3.3 & 3.0 & 1.4 \\
\hline Social status & 4.5 & 3.6 & 3.8 & 2.4 & 3.3 & 3.0 & 1.5 \\
\hline Cooperation & 3.0 & 2.5 & 3.3 & 1.6 & 2.0 & 1.2 & 1.0 \\
\hline Interests sharing & 2.8 & 2.8 & 2.7 & 1.9 & 2.6 & 1.8 & 1.1 \\
\hline Ambition needs & 2.8 & 2.9 & 2.8 & 1.9 & 2.3 & 2.2 & 1.7 \\
\hline Cognitive spontaneity & 3.7 & 3.7 & 3.8 & 3.3 & 3.3 & 3.9 & 3.4 \\
\hline Game elements & 3.5 & 2.8 & 4.0 & 1.8 & 3.5 & 4.1 & 2.6 \\
\hline Active users per month & 16.400 .000 & 1.600 .000 & 980.000 & 350.000 & 50.000 & 10.000 & 100 \\
\hline
\end{tabular}

In order to identify the elements which motivate the people the most to play Match 3-type games, we have verified the level of presence of each motivational element of each game, as well as the quantity of active players per month of each of them, and we have made a comparison among them. For example, if a determined element is strongly present in a game, but at the other its presence is low and the quantity of players of this game is meaningfully shorter than the first, then the element can be considered important, as its absence generated the drop at the quantity of active users of the game.

\section{Results}

Table 2 shows the presence of motivational level results of each game and the quantity of active players per month of each game. The levels of presence were calculated through the 

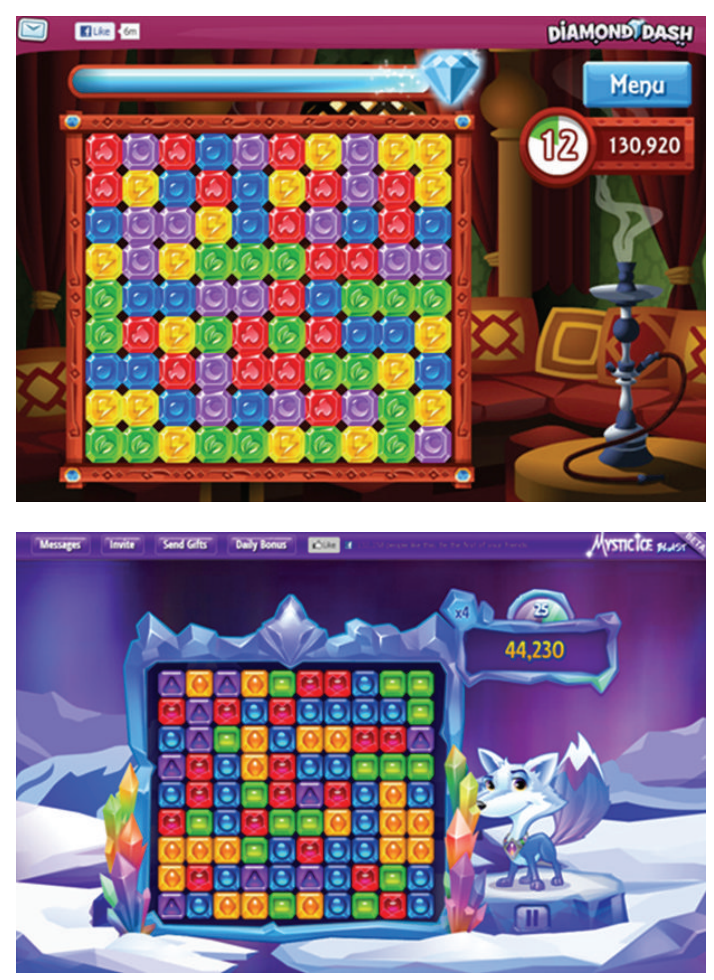

Figure 2: Comparison of the games Diamond Dash and Mystic Ice Blast.

answers average of the participants, and the quantity of active players per month of each game was taken from AppData [4].

The element asynchronous time was strongly present in all the games, with level of presence higher than 4 ; hence, it is realized that the asynchronous gameplay is a very common practice at the Match 3-type games, which makes it necessary the presence of this element at the games.

The most highlighted elements were publications of the activities, rewarding system, competition, and social status, as the level of presence of these elements was higher than 4 only at the game Diamond Dash which is the game which has quantity of active players per month significantly higher than all the other games, a fact which proves the importance of the presence of these elements at the games. Furthermore, in all the other games, these four elements were the ones which were more present compared to all the other items, despite the level of presence being smaller than 4 .

The social fictitious presence, despite of the games being immersed in a social network, is not a very present element in Match 3-type games. In all the games, its presence level was lower than 3. Other elements which are not also used so much at these kinds of games are the interest sharing and ambition needs, which also demonstrated levels of presence lower than 3 in all the games.

Cooperation is not also a very present element at the games; its level of presence was smaller than 4 in all of them, and therefore its presence was relatively higher at the three games with greater quantity of active players: Diamond Dash, Collapse! Blast, and Mystic Ice Blast, with level of presence next to 3, than all the others, having level of presence smaller than 2 . This proves that the cooperation may be a determining factor at the games.

The cognitive spontaneity level of presence was around 3.5 in all the games, a reasonable presence of the element which is enough for the fact that the games are in general simple and intuitive to learn and to play. It is then possible to say that it is not necessary to have detailed explanations on how to play these kinds of games.

Finally, the presence of the elements of game such as arts, sound, story, fantasy, and gameplay were strongly present at the games Mystic Ice Blast and Gem Clix with level of presence equal to 4 . Nevertheless, the presence of these elements did not offer meaningful impacts at the attractiveness of the games, as games like Collapse! Blast demonstrated many more players than both games even with just 2.8 level of presence of these elements. Another example is the game Bricks Breaking which demonstrated more players than Plock, Gem Clix, and Blast!, even having less elaborated elements of the game than these three games.

\section{Discussions and Conclusions}

The results showed that the Match 3-type games have simple gameplay, and they do not show strong points at the fictitious socialization part, and their focus is on the competition and social status, a fact which classifies them at the category of skill/knowledge type of social game defined by Rossi [1], where the main objective is to compete with friends. In fact, the competition and the social status were the elements which were present the most in all the games, which favors the studies by Sherry et al. [23] and Hamari and Järvinen [15], who pointed out competition as the most motivating element of the game.

The importance of the publications of the activities may be related to the viral marketing, as the developers need to bring out their games so that they can reach a great quantity of users, and this publishing takes place when the players publish the activities of the games at the social network site, which generates other possible players and marketers of the game. This practice fits well into the definition of Helm [31] about viral marketing.

The game Bricks Breaking showed unexpected values, as the level of presence of the elements were lower than the games Plock and Gem Clix and even though it showed more active players than these two ones. This confirms that there are other factors which influence the games attractiveness, and we intend in further studies to identify these motivational elements.

This study showed that the main motivational elements of the Match 3-type social games are asynchronous time, publication of the activities, rewarding system, competition, social status, and cooperation. Among them, the publication of the activities, rewarding system, competition, and social status were the ones which demonstrated more influence at the quantity of active players. This can be realized at the game Diamond Dash which was the unique game which demonstrated high level of presence of these items, and it is the game with greater quantity of users. Furthermore, at 
the other games, these four items are the ones which are highlighted the most when compared to the other ones, which leads to the conclusion that the motivation of these games is mainly in these elements.

This paper may help the game designers to project their Match 3-type games with focus on the elements which motivate the most the users to play. We intend in further studies to apply the obtained results in this study in the development of a Match 3-type social game and verify the attractiveness of the game. Moreover, we also intend to identify the main motivational elements of other kinds of games.

\section{Conflict of Interests}

This study does not have any interest to advertise, to criticize, or to judge the games. The authors unique interest is the research, and all the citations related to the games were necessary due to the focus of the research.

\section{References}

[1] L. Rossi, "Playing your network: gaming in social network sites," in Proceedings of DiGRA, 2009.

[2] Facebook, http://newsroom.fb.com/.

[3] D. L. Ines and G. Abdelkader, "Facebook games: between social and personal aspects," International Journal of Computer Information System and Industrial Management Applications, vol. 3, pp. 713-723, 2011.

[4] AppData, http://www.appdata.com/.

[5] D. H. Shin and Y. J. Shin, "Why do people play social network games?" Computers in Human Behavior, vol. 27, no. 2, pp. 852 $861,2011$.

[6] P. Sweetser and P. Wyeth, "Game flow: a model for evaluating player enjoyment in games," ACM Computer in Entertainment, vol. 3, no. 3, pp. 1-25, 2005.

[7] A. Järvinen, "Game design for social networks: interaction design for playful dispositions," in Proceedings of the ACM SIGGRAPH Symposium on Video Games (Sandbox '09), pp. 95-102, ACM, August 2009.

[8] D. M. Boyd and N. B. Ellison, "Social network sites: definition, history, and scholarship," Journal of Computer-Mediated Communication, vol. 13, no. 1, pp. 210-230, 2007.

[9] C. Chang and Y. Chin, "Predicting the usage intention of social network games: an intrinsic-extrinsic motivation theory perspective," International Journal of Online Marketing, vol. 1, no. 3, pp. 29-37, 2011.

[10] V. Donmus, "The use of social networks in educational computer-game based foreign language learning," in Proceedings of the 1st World Conference on Learning, Teaching and Administration (WCLTA '10), pp. 1497-1503, October 2010.

[11] V. Rao, "Facebook applications and playful mood: the construction of facebook as a 'third place," in Proceedings of the 12th International Conference on Entertainment and Media in the Ubiquitous Era, pp. 8-12, fin, October 2008.

[12] International Game Developers Association, "Casual games 2008-2009 white paper," archives.igda.org/casual/IGDA_ Casual_Games_White_Paper_2008.pdf.

[13] D. Y. Wohn, C. Lamp, and R. Wash, "The "S" in social network games: initiating, maintaining, and enhancing relationships," in Proceedings of the 44th Hawwaii International Conference on System Sciences. IEEE Computer Society, Washington, DC, USA, 2011.

[14] J. Sung, T. Bjornrud, Y. H. Lee, and D. Y. Wohn, "Social network games: exploring audience traits," in Proceedings of the 28th Annual CHI Conference on Human Factors in Computing Systems (CHI'10), pp. 3649-3654, April 2010.

[15] J. Hamari and A. Järvinen, "Building customer relationship through game mechanics in social games," in Business, Technological and Social Dimensions of Computer Games: Multidisciplinary Developments, M. Cruz-Cunha, V. Carvalho, and P. Tavares, Eds., Hershey, 2011.

[16] R. V. Meurs, "And then you wait: the issue of dead time in social network games," in Proceedings of DiGRA, Conference: Think Design Play, January 2011.

[17] Y. Benkler, The Wealth of Networks, Yale University, 2006.

[18] M. A. Urista, Q. Dong, and K. D. Day, "Explaining why young adults use MySpace and Facebook through uses and gratification theory," Human Communication, vol. 12, no. 2, pp. 215-229, 2009.

[19] A. N. Joinson, "Looking at, looking up or keeping up with people?: motives and use of facebook," in Proceedings of the Twenty-Sixth Annual SIGCHI Conference on Human Factors in Computing Systems (CHI '08), April 2008.

[20] K. Lucas and J. L. Sherry, "Sex differences in video game play: a communication-based explanation," Communication Research, vol. 31, no. 5, pp. 499-523, 2004.

[21] E. M. Perse and J. A. Courtright, "Normative images of communication media: mass and interpersonal channels in the new media environment," Human Communication Research, vol. 19, no. 4, pp. 485-503, 1993.

[22] J. Hou, "Uses and gratification of social games blending social networking and game play," First Monday Peer-Reviewed Jornal on the Internet, vol. 16, no. 7, 2011.

[23] J. L. Sherry, K. Lucas, B. S. Greenberg, and K. Lachlan, "Video game uses and gratifications as predictors of use and game preference," in Playing Video Games: Motives, Responses, and Consequences, P. Vorderer and J. Bryant, Eds., pp. 213-224, Mahwah, NJ, USA, 2006.

[24] P. Kollock, "The Economies of Online Cooperation: gifts, and public goods in cyberspace," in Communities in Cyberspace, M. A. Smith and P. Kollock, Eds., pp. 220-239, London, UK, 1999.

[25] H. A. Murray, Explorations in Personality, Oxford University, 1938.

[26] J. Hamari and V. Lehdonvirta, "Game design as marketing: how game mechanics create demand for virtual goods," International Journal of Business Science and Applied Management, vol. 5, no. 1, pp. 14-29, 2010.

[27] D. Choi and J. Kim, "Why people continue to play online games: in search of critical design factors to increase customer loyalty to online contents," Cyberpsychology and Behavior, vol. 7, no. 1, pp. 11-24, 2004.

[28] B. Kirman, "Emergence and playfulness in social games," in Proceedings of the 14th International Academic Mindtrek Conference: Envisioning Future Media Environments, pp. 7177, ACM, October 2010.

[29] M. Csikszentmihalyi, The Psychology of Optimal Experience, HarperCollin e-Books, 1990.

[30] J. Schell, The Art of Game Design, Morgan Kaufmann, 2008.

[31] S. Helm, "Viral marketing-establishing customer relationships by 'Word of Mouse'”, Electronic Markets, vol. 10, no. 3, pp. 158-161, 2000.

[32] X. Wei, J. Yang, and J. A. Adamic, "Diffusion dynamics of games on online social networks," in Proceedings of the $3 \mathrm{rd}$ Conference on Online Social Networks (WOSN '10), 2010. 
[33] J. Hamari and J. Tuunanen, "Meta-synthesis of player typologies," in Proceedings of DiGRA Nordic Conference: Local and Global-Games in Culture and Society, 2012.

[34] R. Bartle, "Hearts, clubs, diamonds, spades: players who suit muds," http://www.mud.co.uk/richard/hcds.htm.

[35] N. Yee, "Motivations of play in online games," Journal of Cyber Psychology and Behavior, vol. 9, no. 6, pp. 772-775, 2007. 

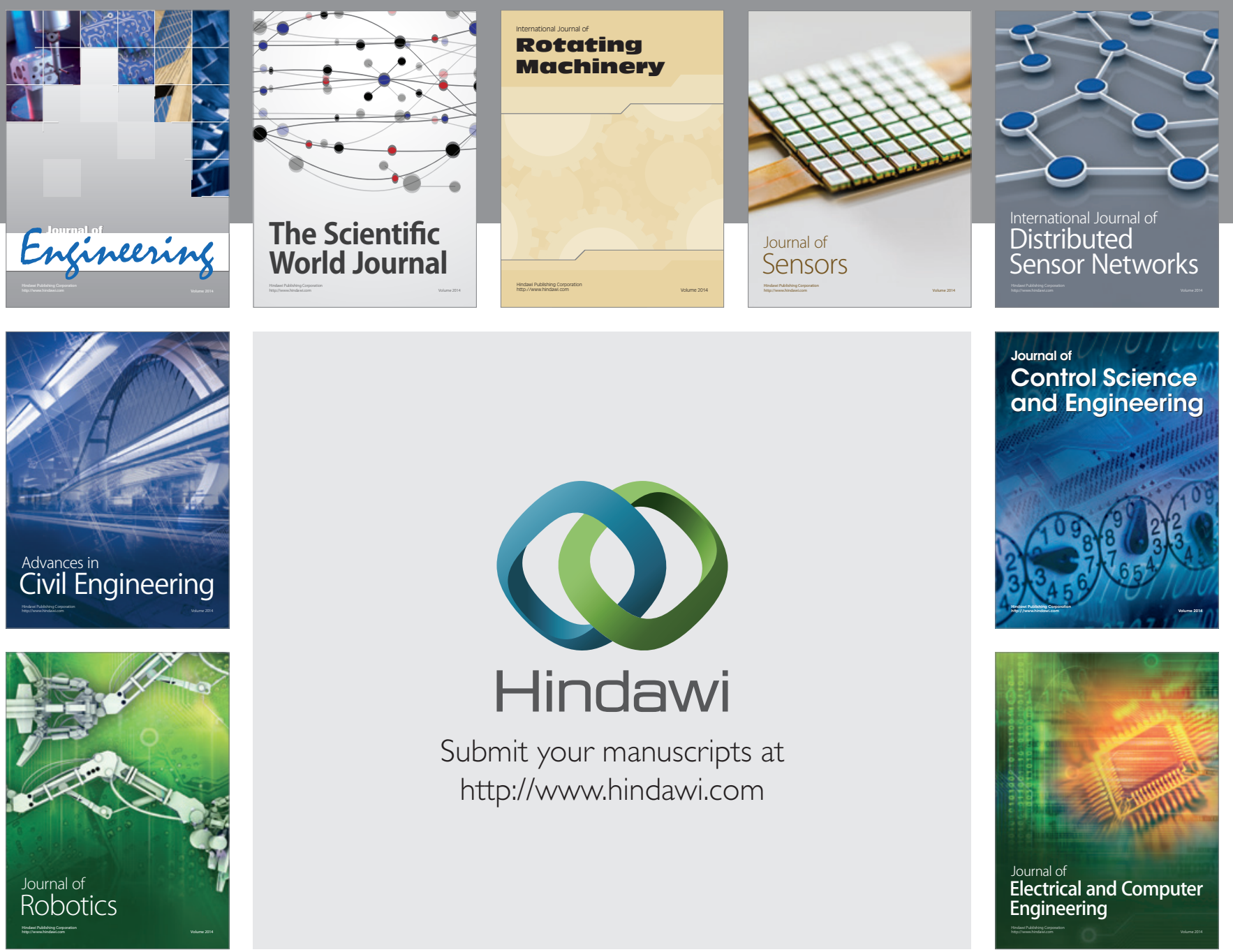

Submit your manuscripts at

http://www.hindawi.com
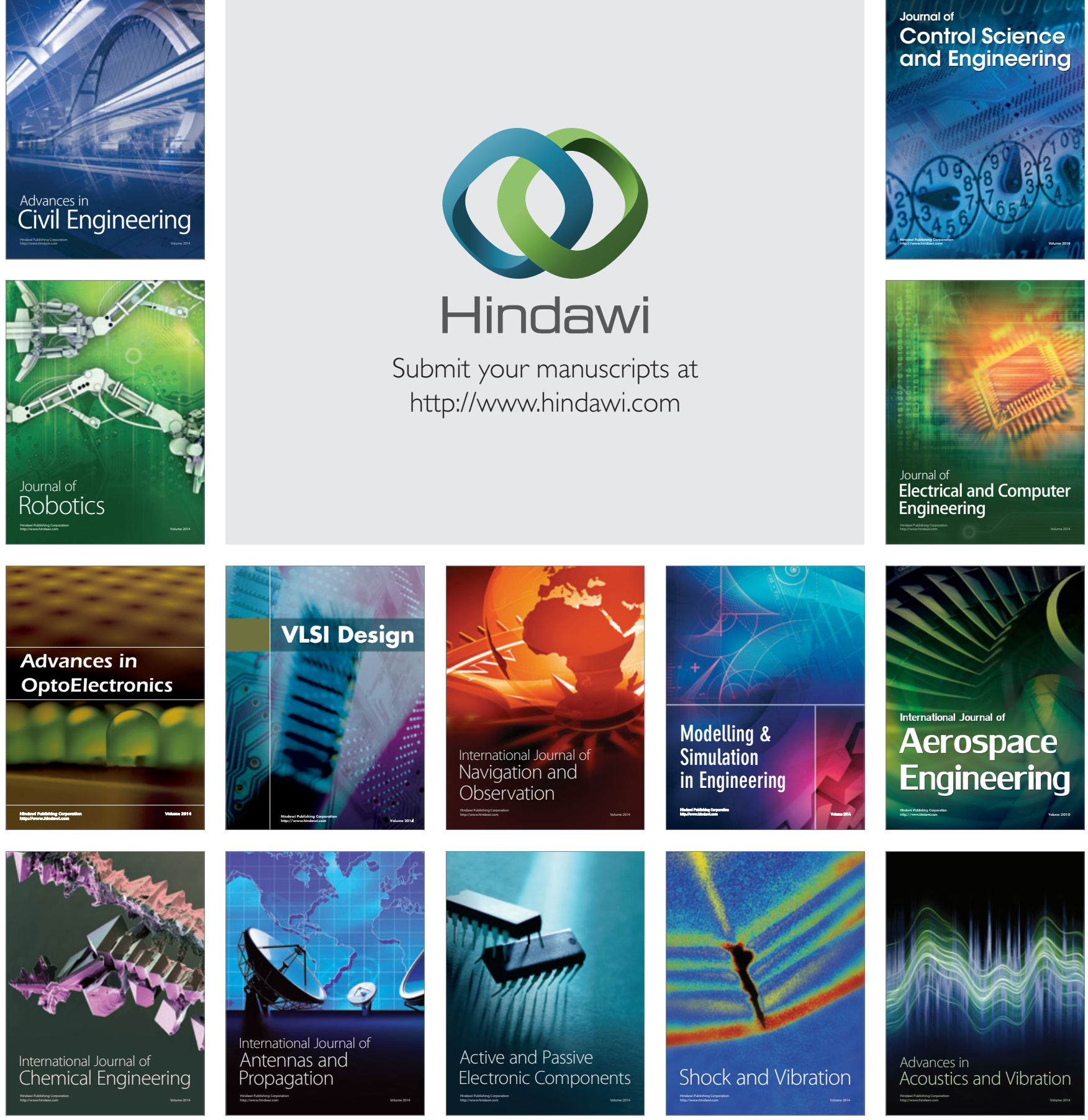